\title{
Correction
}

\section{Correction: Effects of Chronic Sleep Deprivation on the Extracellular Signal-Regulated Kinase Pathway in the Temporomandibular Joint of Rats}

\section{The PLOS ONE Staff}

There is an error in the funding statement. Please refer to the correct funding statement below.

The authors received funding for this study from the following sources.

Grant number:Lu Cai Jiao Zhi (2013) 171;URL: http://www. sdcz.gov.cn/; Funding institution: Shandong Province Finance Bureau; Authors that received the funding: HZ;

Grant number:81400573; URL: http://www.nsfc.gov.cn/; Funding institution: National Natural Science Foundation of China; Authors that received the funding: WG;

Grant number:61471384; URL: http://www.nsfc.gov.cn/; Funding institution: National Natural Science Foundation of China; Authors that received the funding: WG.

\section{Reference}

1. Ma C, Wu G, Wang Z, Wang P, Wu L, et al. (2014) Effects of Chronic Sleep Deprivation on the Extracellular Signal-Regulated Kinase Pathway in the Temporomandibular Joint of Rats. PLoS ONE 9(9): e107544. doi:10.1371/ journal.pone.0107544
Citation: The PLOS ONE Staff (2014) Correction: Effects of Chronic Sleep Deprivation on the Extracellular Signal-Regulated Kinase Pathway in the Temporomandibular Joint of Rats. PLoS ONE 9(12): e114988. doi:10.1371/ journal.pone. 0114988

Published December 1, 2014

Copyright: $\odot 2014$ The PLOS ONE Staff. This is an open-access article distributed under the terms of the Creative Commons Attribution License, which permits unrestricted use, distribution, and reproduction in any medium, provided the original author and source are credited. 